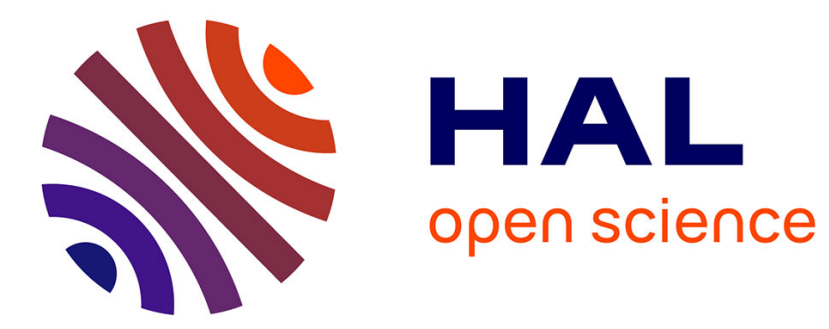

\title{
THE CHEMICAL VAPOUR IMPREGNATION OF POROUS SOLIDS. MODELLING OF THE CVI-PROCESS
}

\author{
E. Fitzer, W. Fritz, G. Schoch
}

\section{- To cite this version:}

E. Fitzer, W. Fritz, G. Schoch. THE CHEMICAL VAPOUR IMPREGNATION OF POROUS SOLIDS. MODELLING OF THE CVI-PROCESS. Journal de Physique IV Proceedings, 1991, 02 (C2), pp.C2-143-C2-150. 10.1051/jp4:1991217 . jpa-00249804

\section{HAL Id: jpa-00249804 https://hal.science/jpa-00249804}

Submitted on 1 Jan 1991

HAL is a multi-disciplinary open access archive for the deposit and dissemination of scientific research documents, whether they are published or not. The documents may come from teaching and research institutions in France or abroad, or from public or private research centers.
L'archive ouverte pluridisciplinaire HAL, est destinée au dépôt et à la diffusion de documents scientifiques de niveau recherche, publiés ou non, émanant des établissements d'enseignement et de recherche français ou étrangers, des laboratoires publics ou privés. 


\title{
THE CHEMICAL VAPOUR IMPREGNATION OF POROUS SOLIDS. MODELLING OF THE CVI-PROCESS
}

\author{
E. FITZER, W. FRITZ and G. SCHOCH \\ Institut für Chemiche Technik der Universität Karlsruhe, \\ Kaiserstrasse 12, D-7500 Karlsruhe 1, Germany
}

\begin{abstract}
The paper presents a model of the CVD- and CVI- proceses based on the principles for the description of the gas solid reactions on the outer surface of the substrate and the inner surface of the pores.

The model parameters mass transfer coefficient and rate constant of the chemical reaction at the surface were determined experimentally.

The model for the inpore deposition takes into account that during the CVI- process the geometry of the pores changes and thus no steady state is reached during the process.

The precalculation of the CVI- effect using the above model and experimental results are compared for demonstration of the applicability of the mathematical model.

Also for porous substrates with a pore size distribution the model describes quantitatively the impregnation effect. The experimental demonstration was performed as SiC- CVI of substrates with micropores between 3 and $15 \mu \mathrm{m}$ in diameter and as SiC- CVI of SiC- whisker sheets with a diameter distribution ranging from $0.1 \mu \mathrm{m}$ to $200 \mu \mathrm{m}$.
\end{abstract}

\section{INTRODUCTION}

The chemical vapour infiltration (CVI) of porous solids is an important method for densification. Compared to other techniques such as liquid phase impregnation it has the advantage that no volatile by- products have to penetrate an already formed layer. This means that no open porosity is generated by escaping volatile products during pyrolysis.

The most important disadvantage of the CVI process, however, is the long reaction time required due to the fact that it has to be run under conditions that guarantee that the rate of mass transport by diffusion is at least at the same level as that of the chemical reaction, i.e. at low temperatures and under reduced pressure.

since the result of a CVI- treatment depends on many variables (reaction temperature, total pressure, concentration of the precursor in the gas phase and flow conditions) an experimental optimization of the process is very time consuming and expensive.

For this reason considerable efforts are made to find theoretical concepts permitting one to calculate the properties, i.e. open and closed porosity, of the solid after densification $(1-4)$. 


\section{THEORETICAL CONSIDERATIONS}

\subsection{The mathematical model}

The description of the CVD- and CVI processes is based on chemical engineering kinetics as described elsewhere $(5,6)$.

The details of the mathematical treatment of the CVD and CVI- processes have been published previously $(7,8)$ so that in this paper only the most important equations finally leading to a calculation of the residual open and closed porosity after CVI will be presented.

Fig. 1 schematically shows the process of the formation of a deposit by a hererogeneous reaction at the inner surface of a pore:

The gaseous precursor has to penetrate the laminar boundary layer at the outer surface (1). Then it is transported by diffusion into the pore (2) and physically or chemically adsorbed at the inner surface (3), where the chemical reaction takes place (4) before the volatile by- products are desorbed (5). Finally the gaseous by- products are transported to the outer surface by diffusion (6) before they penetrate the laminar boundary layer to reach the bulk gas phase (7).

In the mathematical model to be presented here it is assumed that there is no influence of the ad- and desorption and of the diffusion of the byproducts $(\mathrm{HCl})$ on the kinetics of the overall process. This means that only the mass transfer of the educt to the outer surface (step 1), its diffusion into the pore (step 2) and the chemical reaction at the inner surface (step 4) influence the overall process.

The material balance for a reactant $A$ inside a pore is given by:

$$
D_{e} \frac{d^{2} C_{A}}{d z^{2}}+r_{v} v_{A}=0
$$

Under the assumption of a steady state the material balance can be integrated for a first order reaction:

$$
c_{A}=C_{A, S} * \frac{e^{\sqrt{D a_{I I}}(1-z / L)}+e^{-\sqrt{D a_{I I}}(1-z / L)}}{e^{\sqrt{D a_{I I}}}+e^{-\sqrt{D a_{I I}}}}
$$

where for a first order reaction the ratio

$$
D a_{I I}=\frac{k_{V} L^{2}}{D_{\theta}}=\frac{k_{S}\left(A_{\text {in }}\right)_{V} L^{2}}{D_{\theta}}
$$

is called $2^{\text {nd }}$ Damköhler number and describes the ratio between the rate of the chemical reaction at the inner surface of the substrate and the rate of material transport by diffusion (9). In this equation $k_{s}$ is the rate constant of the chemical reaction, $D_{e}$ the effective diffusion coefficient, $I$ the pore length and $\left(A_{i n}\right)_{v}$ the inner surface per volure. For a cylindrical pore $\left(A_{\text {in }}\right)_{v}=2 / r$.

The equations presented up to here presuppose a reaction under steady state conditions. Since the purpose of a CVI- process is the deposition of a layer on the inner surface of the pores, the value for $\left(A_{i n}\right)_{v}$ is not constant leading to a variable $\mathrm{Da}_{11}$ - number.

In order to take this into account, the model represented by the eqs. (1) to (3) has to be modified by introducing subdivisions for the pore length and the reaction time. For each time interval steady state conditions are assumed. By integration of the material balance within the limits $x_{0}=0$ and $z=L / n$ ( $n=$ number of subdivisions) one obtains: 


$$
\overline{I_{A}}=n k_{S} C_{A, s} \frac{\cosh \sqrt{D a_{I I}}-\cosh \left[\sqrt{D a_{I I}}\left(1-\frac{1}{n}\right)\right]}{\sqrt{D a_{I I}} \cosh \sqrt{D a_{I I}}}
$$

In eq. (4) $C_{A, S}$ is calculated using the equations

$$
\begin{aligned}
& C_{A, S}=\frac{\beta C_{A, P}}{\beta+k_{S}\left[1+\eta\left(A_{i n} / A_{\theta x}\right)\right]} \quad \text { (5a) where } \\
& \eta=\frac{\tanh \sqrt{D a_{I I}}}{\sqrt{D a_{I I}}} \text { and }\left(A_{i n} / A_{e x}\right)=\frac{4 L}{n d}
\end{aligned}
$$

The eqs. (5a) and (5b) are inserted into eq. (4) leading to values for the effective reaction rate in the first interval of the pore length. With increasing number of subdivisions $(n-\rightarrow \infty)$ this becomes equivalent to a reaction rate at the pore entrance. Using eq. (2) the concentration and thus the layer thickness growth can be calculated as a function of the local coordinate $z$. Using eq. (4) the pore diameter at the end of the first reaction time interval can be calculated:

$$
d_{t+\Delta t}=\left[d_{t}^{2}-\frac{d_{t} 4 M_{S i c} k_{S} C_{A} \Delta t}{\rho_{S i C}}\right]^{1 / 2}
$$

From eq. (6) the increase of the layer thickness $\Delta$ s during the reaction time interval $\Delta t$ can be obtained. Using eq. (2) the layer thickness in the other length intervals can be calculated. With the diameter of the pore at the pore entrance after the reaction time interval $\Delta t$ a new $\mathrm{Da}_{\mathrm{II}}$ number is calculated. With this the layer thickness increase during the next reaction time interval is calculated for each length interval. This iteration is repeated until either the re-action time has passed or for the diameter of the pore at the pore en-trance the value zero is calculated, i.e. the pore at the pore entrance is closed.

Up to here, the model is only valid for cylindrical pores with one defined diameter. Since practically all technically relevant substrates exhibit a pore diameter distribution, an extension of the model is nessessary in order to take into account the effect of this pore diameter distribution on the predicted layer thickness profile and thus on the calculated porosity.

The volume of a pore after infiltration can approximately be calculated:

$$
v(t)=\sum_{i=1}^{n} \frac{\pi d^{2}(1, t)}{4} z \quad \text { where } \quad z=\frac{L}{n} \quad \text { and } \quad I=i z
$$

The part of the pore $T_{p}(t)$ that is not yet filled at the time $t$ then follows from:

$$
T_{p}\left(t, d_{0}\right)=\frac{V(t)}{V(t=0)}
$$

For substrates with a pore radii distribution the porosity at the time $t, x_{p}(t)$ can be calculated using eq. (9):

$$
X_{P}(t)=X_{P}(t=0) \int_{d_{0, \text { min }}}^{d_{0, \max }} T_{P}\left(t, d_{o}\right) F\left(d_{0}\right) d d_{0}
$$


In eq. (10) $T_{p}\left(t, d_{0}\right)$ is calculated using eq. (9), when $F\left(d_{0}\right)$ is the frequency with which pores with an initial diameter of $d_{0}$ occur at the time $t=0$.

The equations reported here show that it should be possible to precalculate the result of the CVI- process if the kinetics of the chemical reaction at the outer surface of the substrate, the effective diffusion coefficient and the pore radii distribution of the substrate before the impregnation are known.

\subsection{Calculated layer thickness- depth profiles}

The Figs. 2 to 4 show the results of calculations of the state after pore closure based on the above model for the deposition of Sic from methyltrichlorosilane.

In Fig. 2 the effect of the deposition temperature on the expected layer thickness profile is shown. One can recognize that the profile becomes steeper as the deposition temperature increases. Yet even at the very low temperature of $850^{\circ} \mathrm{C}$ and for relatively large pores with an initial diameter of $100 \mu \mathrm{m}$ there is a measurable difference between the layer thickness at the pore entrance and at the end of the pore $(z=5 \mathrm{~mm})$.

In Fig. 3 the influence of the total pressure on the layer thickness profile is shown. As expected from the mathematical model, the layer thickness profile becomes less uniform as the total pressure increases.

In Fig. 4 finally the influence of the initial diameter on the layer thickness profile is shown in terms of a relative layer thickness (ratio beetween the layer thickness at the position $z$ and the layer thickness at the pore entrance) as a function of the local coordinate $z$. In agreement with the expectation from the mathematical model the layer thickness profile becomes less uniform as the initial pore diameter decreases. This can be explained with an increasing influence of KNUDSEN- diffusion on the effective diffusion coefficient and with an increasing value of the $\mathrm{Da}_{11}$ - number due to an increasing value for $\left(A_{i n}\right)_{v}$.

\section{EXPERIMENTAL PROCEDURE}

The experimental verification of the above model was performed for the deposition of $\mathrm{SiC}$ from methyl trichlorosilane (MTS, $\mathrm{H}_{3} \mathrm{CSiCl}_{3}$ ) in a resistance heated tubular flow reactor under reduced pressure (50-500 mbar) at temperatures between 850 and $1100{ }^{\circ} \mathrm{C}$ using hydrogen as a carrier gas. Fig. 5 shows the scheme of the apparatus used. The substrates used were

- glasslike carbon to measure the kinetics of the chemical reaction at the outer surface of the substrate

- dense cubes of synthetic graphite into which holes were drilled mechanically

- Sic- whisker sheets as substrates with a broad pore radii distribution $\left(0.1 \mu \mathrm{m} \leq \mathrm{d}_{0} \leq 200 \mu \mathrm{m}\right)$.

\section{RESULTS}

4.2 Chemical vapour deposition of SiC in model pores

Samples with mechanically drilled model pores were infiltrated with $S$ ic under varying conditions. The infiltrated samples were cut perpendicular to the pore axis at defined distances from the initial surface and the cross sections were investigated in a scanning electron microscope. Typical micrographs are shown in Fig. 6. In the upper part the surface and a cross section at $z=3 \mathrm{~mm}$ of a dense synthetic graphite infiltrated with Sic are shown. One can recognize the good contrast between the CVDSiC and the base material so that the layer thickness can be measured directly.

Fig. 7 shows experimental and calculated values for the layer thickness profile in model pores with an initial pore diameter of $1000 \mu \mathrm{m}$ and 
$34 \mu \mathrm{m}$ respectively infiltrated under very different experimental conditions. The symbols represent measured, the lines calculated values. The Figure shows a good aggreement between measured and calculated values for pores with a uniform diameter at the pore entrance.

The good correspondence between measured and calculated layer thickness profiles for pores with very different initial diameters encouraged to calculate the residual porosity of a porous substrate after impregnation. This was done for Sic- whisker sheets. The sheets were prepared by filtration of the whiskers from a suspension in butanone leading to bricks of randomly oriented whiskers. From this and the geometry of the whiskers follows a Gaussian distribution for the pore diameters within the limits $0.1 \mu \mathrm{m} \leq \mathrm{d}_{0} \leq 200 \mu \mathrm{m}$. Using the mathematical model presented here the residu-al open porosity of the sic- whisker sheets was calculated for a deposi-tion temperature of $900{ }^{\circ} \mathrm{C}$ and $1000{ }^{\circ} \mathrm{C}$ respectively, for total pressures ranging from 100 mbar to 500 mbar and for reaction times up to 20 hours. The results are shown in Fig. 8. In this figure the closed porosity is taken as a measure for the success of the CVI- treatment. The iines re-present the results of the calculation, the symbols represent values mea-sured by water adsorption. One can recognize that in all cases the calcu-lated values are in good aggreement with the measured ones, particularly for the high deposition temperature. This is due to the fact that at a deposition at $1000{ }^{\circ} \mathrm{C}$ the porosity is higher than at $900{ }^{\circ} \mathrm{C}$ leading to a less important experimental error in water adsorption experiments (3\%).

one can recognize furthermore that under all conditions a more or less important open porosity is built up as predicted by the model.

\section{SUMMARY AND DISCUSSION}

A mathematical model for the CVI- process has been presented based on well known principles for the description of heterogeneous reactions at the inner surface of porous solids. It includes the kinetics of the chemical reaction in terms of the rate constant of the surface reaction and the mass transfer coefficient, the effective diffusion coefficient composed of the binary diffusion coefficient and that for KNUDSEN- diffusion as well as the geometry of the pore.

By iterative calculation the model takes into account that due to changes of the pore diameter at the pore entrance there is no steady state.

Using kinetic data for the deposition of SiC from MTS reported elsewhere (8) layer thickness- depth profiles were calculated. The results of these calculations were compared with profiles measured for cylindrical model pores with a uniform initial diameter as well as for pores with a pore radii distribution.

The agreement between measured and calculated values was good for very different pore diameters.

This leads to an extention of the model taking into account the effect of a pore size distribution on the result of the CVI- process. Using the extended model the closed porosity of Sic- whisker sheets after cVI were calculated. The comparison between the calculated and measured values leads to the conclusion that the model presented here reasonably describes the CVI process.

\section{REFERENCES}

(1) H.J. Bühler, Thesis, Universität Karlsruhe, 1976

(2) R. Naslain et al., Adv. in Comp. Mat., 2, (1980) $1084-1097$

(3) J.Y. Rossignol, F. Langlais, R. Naslain Proc. of the $9^{\text {th }}$ Int. Conf. on CVD, 1984, The Electrochem. Soc., Pennington, N.J., pp. 596-624

(4) R. Fedou, F. Langlais, R. Naslain Proc. of the $11^{\text {th }}$ Int. Conf. on CVD, Oct. 1990, seattle, USA, in print

(5) E. Fitzer, W. Fritz

Einführung in die chemische Reaktionstechnik, Springer Verlag, Berlin, Heidelberg, New York, 3. Auflage, 1989 
(6) M. Baerns, H. Hoffmann, A. Renken

Lehrbuch der Technischen Chemie, Bd. 1, Georg Thieme Verlag, Stuttgart, New York, 1. Auflage, 1987

(7) W. Wittenberger, W. Fritz, Rechnen in der Verfahrenstechnik und chemischen Reaktionstechnik, Springer Verlag, Wien, New York, 1986

(8) E. Fitzer, W. Fritz, G. Schoch High Temperatures, High Pressures, Vol. 22 (1990) in print

(9) G. Schoch, Thesis, Universität Karlsruhe, 1990

(10) G. Damköhler in:

Der Chemieingenieur, A. Eucken, M. Jakob eds. Akad. Verlagsges. Leipzig, Bd. III/1, 1937, pp. $359-485$

\section{TABLES AND FigURES}

Reaction equation:

$\mathrm{H}_{3} \mathrm{CSiCl}_{3}------>\mathrm{SiC}+3 \mathrm{HCl}$

Kinetic parameters taken from ( 8 )

Experimental conditions:

Deposition temperature:

Total pressure:

$800-1100{ }^{\circ} \mathrm{C}$

50 - 500 mbar

Molar fraction of MTS in the gas phase: $0.25-0.6$ Balance: $\mathrm{H}_{2}$

Gas velocity at room temperature:

$0.31 \mathrm{~cm} / \mathrm{s}$

Tab. I Reaction equation and experimental conditions for the deposition of SiC from MTS
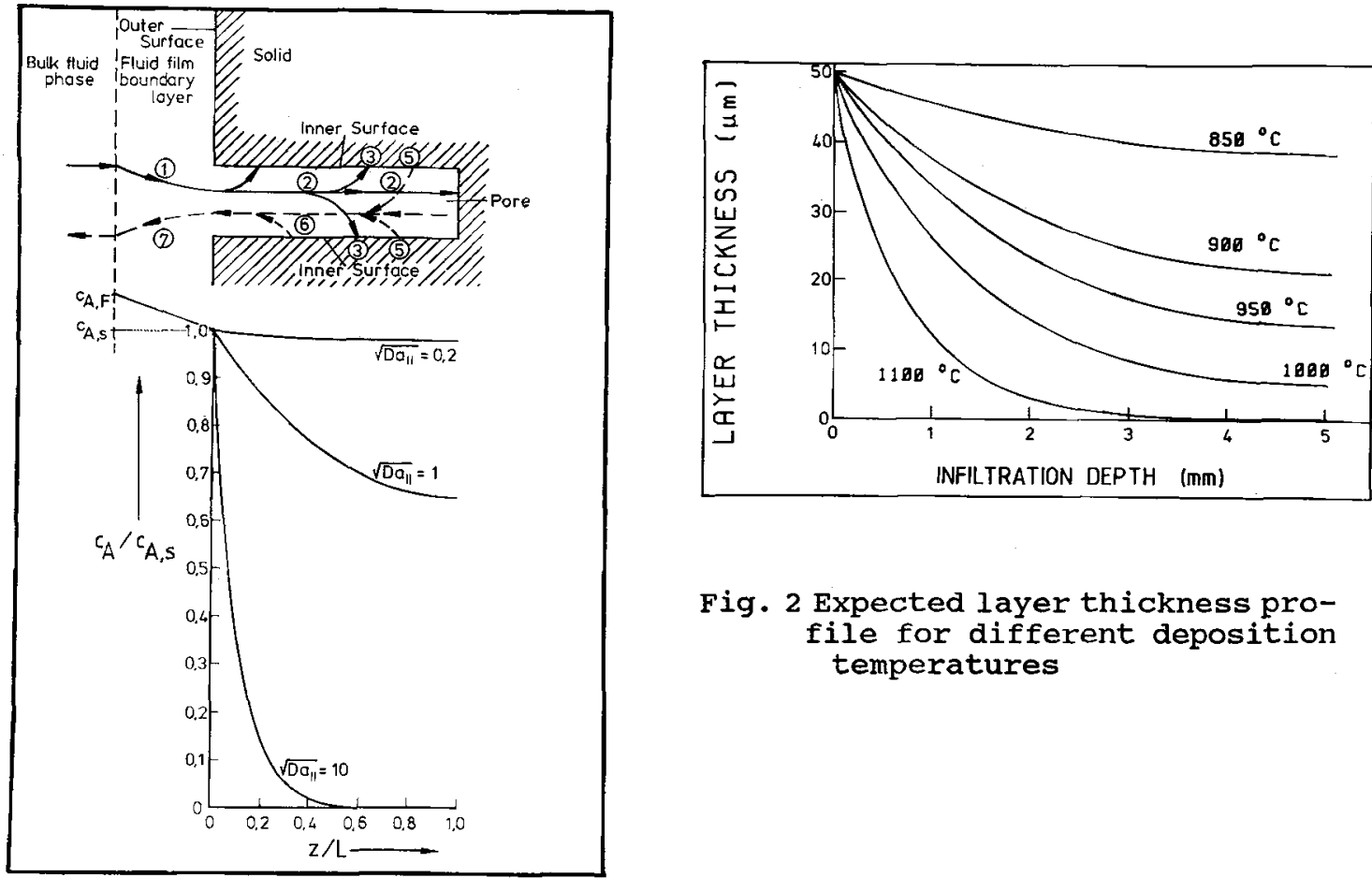

Fig. 2 Expected layer thickness profile for different deposition temperatures

Fig. 1 Process of inpore deposition (schematically) 


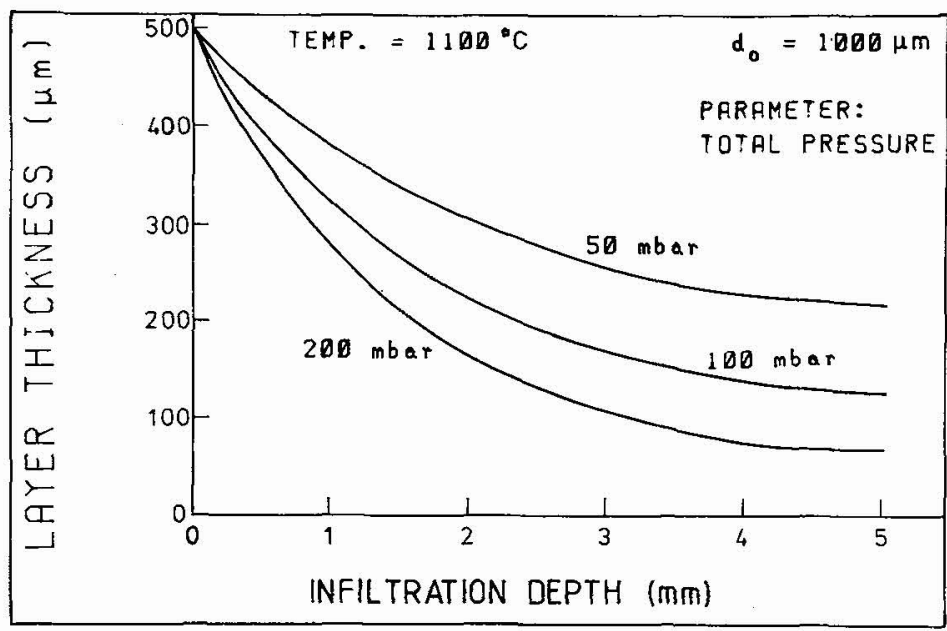

Fig. 3 Influence of the total pressure on the layer thickness profile

Fig. 4 Influence of the initial pore diameter on the relative layer thickness profile
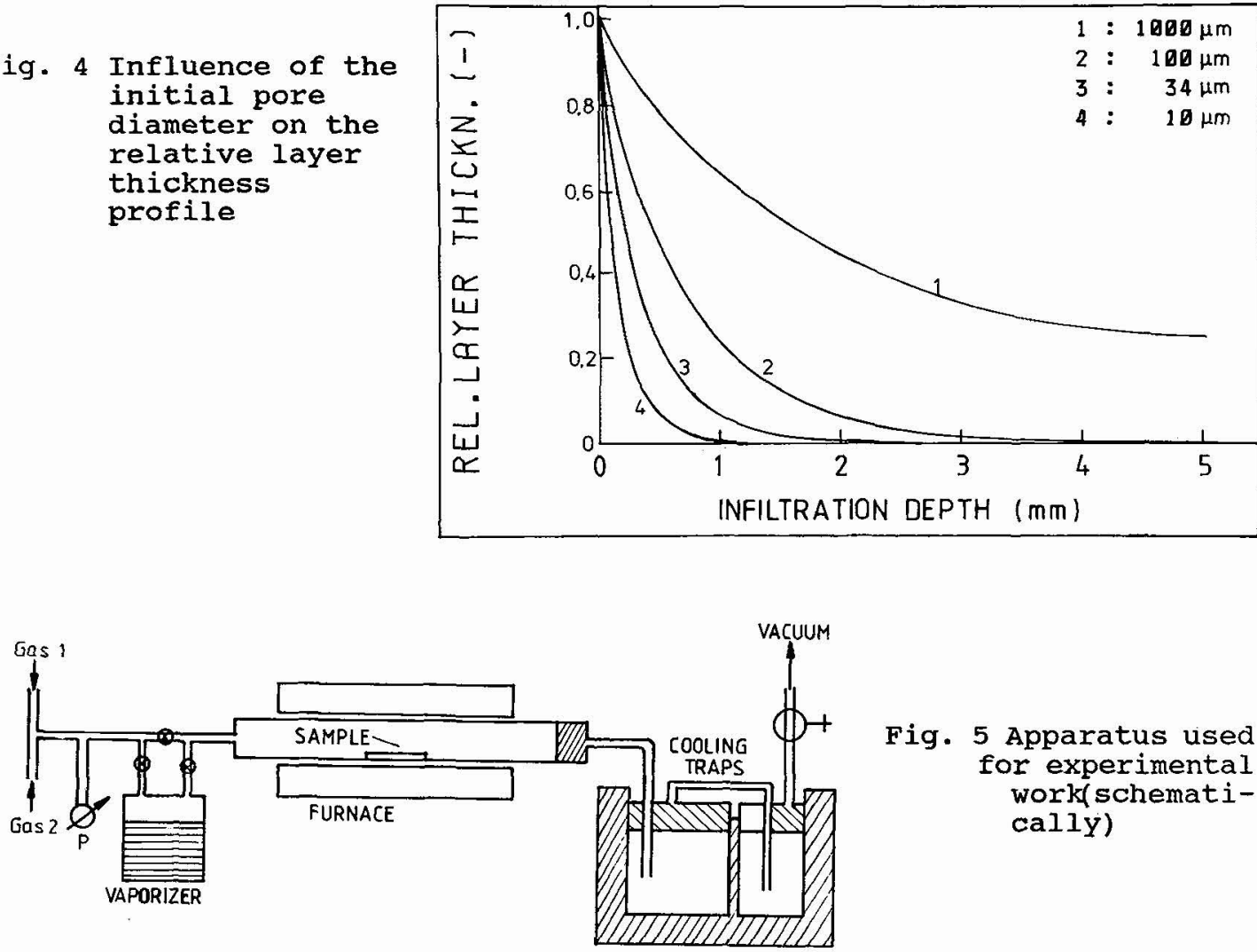

Fig. 5 Apparatus used for experimental work) (schematically) 


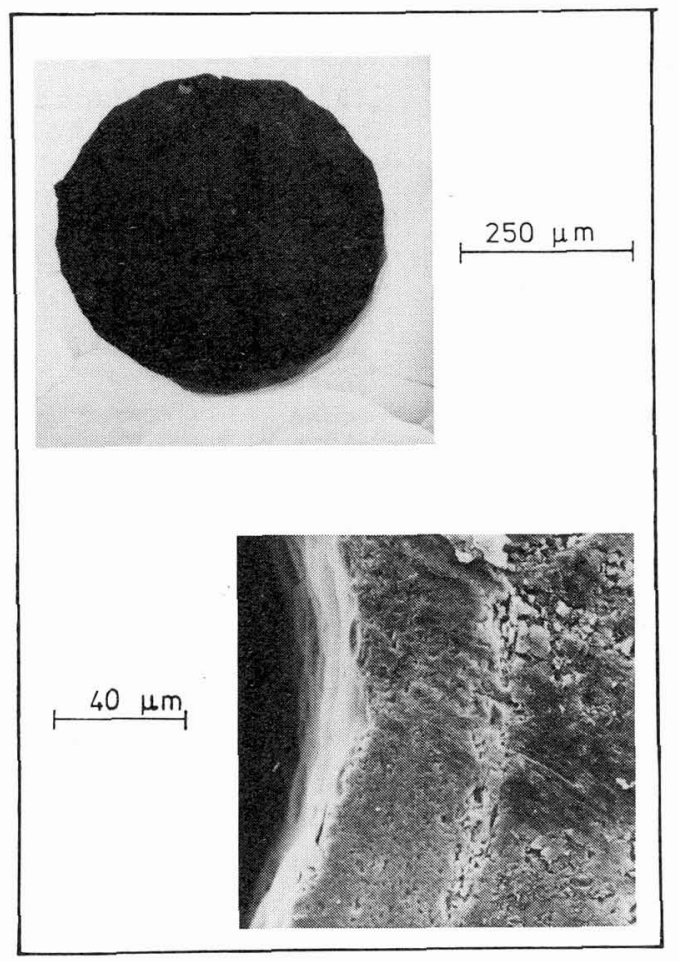

Fig. 6 Typical SEM- micrographs used for the measurement of the layer thickness in pores
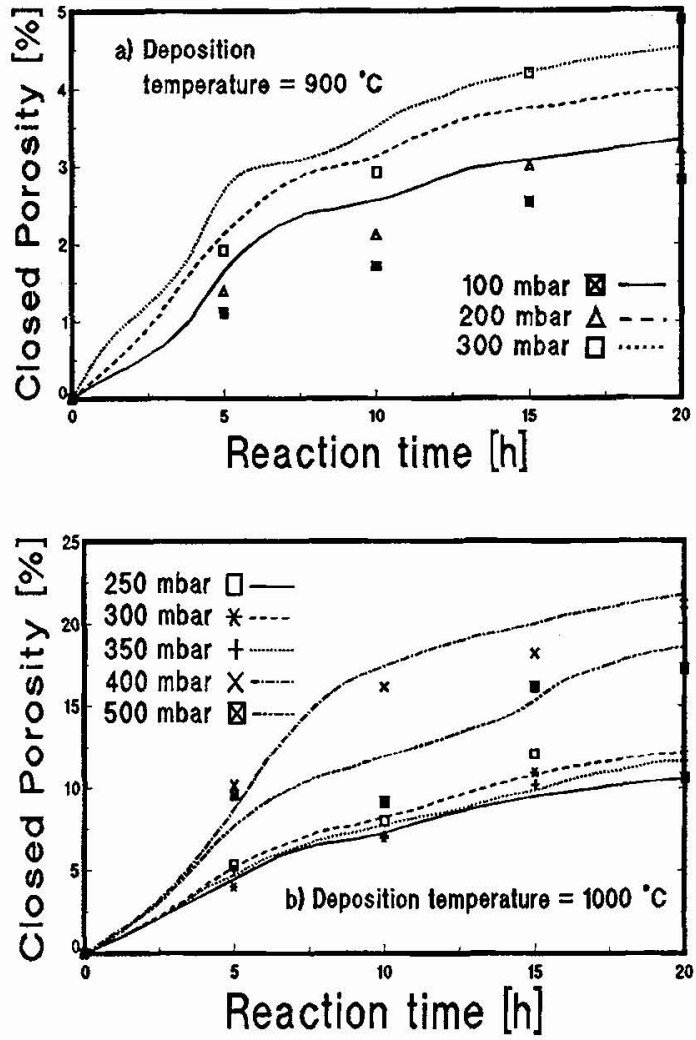

Fig. 8 Measured (symbols) and calculated (lines) closed porosity of SiC- whisker sheets after CVI

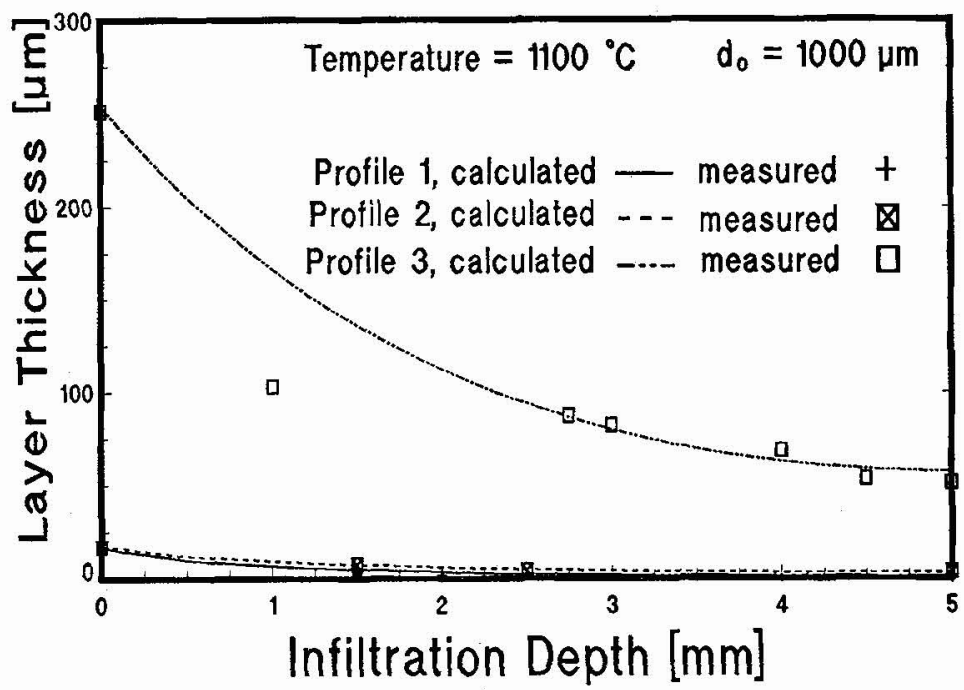

Fig. 7 Experimental (symbols) and calculated (lines) layer thickness profiles 